\title{
Maturity Assessment of Railway Station Business District on the Entropy Fuzzy Synthesis Evaluation Model
}

\author{
Wenwei Dai* \\ Institute of Economics and Management \\ Beijing Jiaotong University \\ Beijing, China \\ lauradai2013@gmail.com \\ *Corresponding author
}

Abstract- In combination with the actual situation and the characteristics of the railway station business district in China, we formed the railway station business district maturity model, and applied both entropy method and fuzzy comprehensive evaluation method to the station business district maturity model evaluation. The establishment of entropy fuzzy comprehensive evaluation model for a large number of fuzzy factors existing in the railway station business district can increase the scientific nature and the reliability of the evaluation results. This article, using the method to evaluate Beijing railway station, Beijing west railway station, Shanghai railway station and Shanghai Hongqiao railway station business district, then makes an example to verify the accuracy of the results, and puts forward the development strategy of Hongqiao railway station.

Keywords- entropy value; fuzzy evaluation; railway station business district; maturity

\section{INTRODUCTION}

In our country, the railway stations have been the central of the city, and been the "node" area for contacting city-city transmission and the inner-city traffic .Most western countries regard the reconstruction or expansion of urban central railway station as the "catalyst" of redeveloping the core region, and the railway station area often set the business, commerce, catering, leisure business form. In recent years, some domestic cities start to do the rectification and new construction of the railway station, such as Guangzhou east railway station, Shanghai south railway station, etc. Now the railway station business districts of China have transformed from traffic complexes to the city complexes, and from the transportation hub towards regional economic hub. The rapid development of business district makes the evaluation on business district maturity become inevitable, maturity of business district has also become one of the important performances for the station's power.

\section{THE CONCEPT OF MATURITY OF STATION BUSINESS DISTRICT}

\section{A. Grading of Maturity of the Station Business District}

The concept of Maturity comes from CMM (Capability Maturity Model For software), a software evaluation standard which was studied, established, promoted and implemented by Carnegie Mellon university of software engineering institute

\author{
Gaixia Guan \\ Institute of Economics and Management \\ Beijing Jiaotong University \\ Beijing, China \\ 497663250@qq.com
}

(CMU/SEI) commissioned by the U.S. defense department, mainly used in the evaluation and improvement of the software development process and ability. According to the history and status quo of software production, CMU express it at five continuously evolved levels: the initial level, the repeatable level, the defined level, the managed level, the optimizing level.

Introducing maturity into the railway station business district, according to the development of railway station business district and the discretion of the hierarchy, the station business district maturity is defined into four levels. Four levels respectively are: immature, less mature, more mature and mature.

\section{B. Considerations of the Station Maturity Evaluation}

The design of evaluation index system of the railway station business district, involves not only such principles as scientificity, operability, comparability, comprehensiveness, independence, but also the characteristics of the theme and development status of the railway station business district. Mainly from three aspects such as the resource configuration of the business district, the scale of the station, the business conditions of the existing station business district, we put forward seven major indexes to evaluate the maturity of the railway station business district. They respectively are: resources, commercial resources gross occupation area, passenger flow, the station train scale, the reception capacity, the catering ability, traffic conditions.

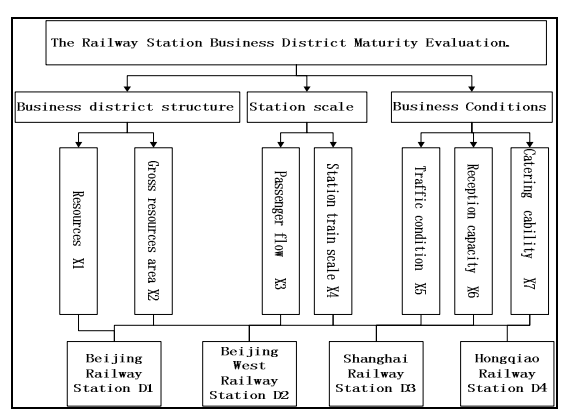

FIGURE I. THE EVALUATION SYSTEM OF THE STATION BUSINESS DISTRICT MATURITY 


\section{THE CONSTRUCTION OF THE ENTROPY FUZZY COMPREHENSIVE EVALUATION MODEL}

\section{A. Evaluating Matrix by Fuzzy Relations}

Set we need evaluate the station business districts through different evaluation indexes, the number gained from the research of the actual data. According to the evaluation results of each station business district maturity, we get evaluation matrix $X$ as follows:

$$
X=\left(\begin{array}{cccc}
x_{11} & x_{12} & \ldots & x_{1 n} \\
x_{21} & x_{22} & \ldots & x_{2 n} \\
\ldots & \ldots & \ldots & \ldots \\
x_{m 1} & x_{m 2} & \ldots & x_{m n}
\end{array}\right)
$$

Among which, $x_{i j}$ said the evaluation results of the staff $i$ and the factor $j$.

As all kinds of valuation factors reflecting the station maturity often have different dimension and dimension unit, in order to eliminate the resulted indexes incommensurability, we apply a dimensionless processing to evaluation indexes through the use of extreme values transferring method, specific practices are as follows:

$$
\text { For index, make } r_{i j}=\frac{x_{i j}-x_{\min (j)}}{x_{\max (j)}-x_{\min (j)}}
$$

Through the above changes, we can get the fuzzy relation judgment matrix $R$ :

$$
R=\left(\begin{array}{cccc}
r_{11} & r_{12} & \ldots & r_{1 n} \\
r_{21} & r_{22} & \ldots & r_{2 n} \\
\ldots & \ldots & \ldots & \ldots \\
r_{m 1} & r_{m 2} & \ldots & r_{m n}
\end{array}\right)
$$

Among which, $r_{i j}$ is dimensionless result of the original data $x_{i j}$, said the evaluation coefficient of the evaluation results of the train station $i$ and the evaluating factor $j, 0 \leq r_{i j} \leq 1$.

\section{B. Applying Entropy Value Method to Determine the Weight of Evaluation Index}

Calculating the weight of the index $r_{i j}$ in the index $j$;

Then the index $j$ entropy is: $e_{j}=-k \sum_{i=1}^{m} P\left(r_{i j}\right) \ln P\left(r_{i j}\right)$

$$
P\left(r_{i j}\right)=\frac{r_{i j}}{\sum_{i=1}^{m} r_{i j}}
$$

Among them, $k>0, k=1 / \ln m, e_{j} \geq 0$.

In the formula, $P\left(r_{i j}\right)=r_{i j} / \sum_{i=1}^{m} r_{i j}$, When $P\left(r_{i j}\right)=0, \ln P\left(r_{i j}\right)$ is meaningless, so the calculations of $\ln P\left(r_{i j}\right)$ should be amended, it will be defined as:

$$
P\left(r_{i j}\right)=\frac{1+r_{i j}}{\sum_{i=1}^{m}\left(1+r_{i j}\right)}
$$

So we can get the difference function $g_{j}=1-e_{j}$ of index $j$. For a given index $j$, the smaller the difference of the $r_{i j}$ is, the greater the ${ }^{e_{j}}$ will be; When ${ }^{r_{i j}}$ are all equal, ${ }^{e_{j}}=1$, at this time the index $j$ plays almost no role; When the bigger the difference of each evaluation index is, the smaller the ${ }^{e_{j}}$ is, the bigger the index's role for evaluation objects will be. So when the greater the ${ }^{g_{j}}$ is, the more important indicators will be. Weight vector of the index can be defined as: $A=\left(a_{1}, a_{2}, \ldots, a_{n}\right)$, among which:

$$
a_{i}=g_{j} / \sum_{i=1}^{m} g_{j}
$$

\section{Entropy Fuzzy Comprehensive Evaluation Model}

From the above R and A, the fuzzy mathematics fuzzy matrix synthesis operator was used to get fuzzy comprehensive evaluation sets:

$$
B=A \cdot R^{T}=\left(b_{1}, b_{2}, \ldots, b_{n}\right)
$$

The above formula is the entropy fuzzy comprehensive evaluation model, $b_{1}, b_{2}, \ldots, b_{n}$ is the comprehensive evaluation sets for the station business district.

\section{Determining Membership Functions}

Make $\mathrm{V}=$ (not mature, less mature, more mature and mature), as the railway station maturity fuzzy sets, as for any one element bi of $\mathrm{B}$, there is a number $\mathrm{V}(\mathrm{x}) \in 0,1$ matching, said the $\mathrm{V}$ is the fuzzy sets for $\mathrm{B}, \mathrm{V}(\mathrm{x})$ is called for the membership degree of bi to $\mathrm{V}$. When bi changes in $\mathrm{B}, \mathrm{V}(\mathrm{x})$ is a function, called the membership functions. The closer to 1 the membership degree $\mathrm{V}(\mathrm{x})$ is, the higher the level of bi for $\mathrm{V}$ is; the closer to 0 the membership degree $\mathrm{V}(\mathrm{x})$ is, the higher the level of bi for $\mathrm{V}$ is. Using the membership function $\mathrm{V}(\mathrm{x})$ from interval 0 and 1 represent the membership degree of bi for V.

According to the grading of the railway station business district maturity, maturity membership degree within the $[0,1]$ is divided into four stages, respectively drawing the membership degree function curves, as shown in FIG. 2:

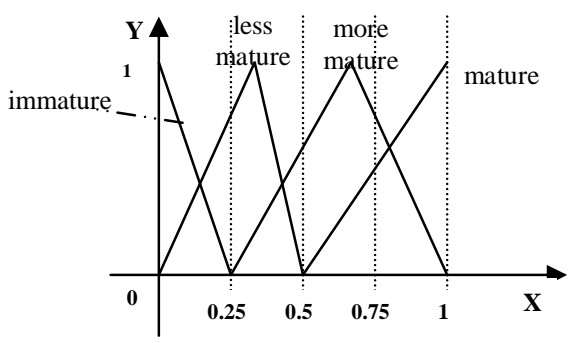

FIGURE II. THE MEMBERSHIP DEGREE FUNCTION CURVES 
According to the Fig. 2, four stages of the membership function $\mathrm{V}(\mathrm{x})$ shown as follows:

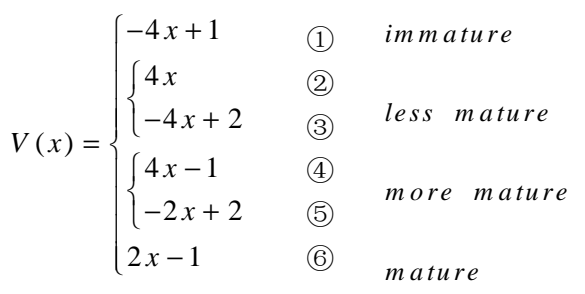

Introduce bi into the membership function formula, in $[0,0.25]$, respectively (1) and (2), select larger membership degree as the maturity evaluation results of bi; in $[0.25,0.5]$, into formula(3) and (4)for comparison; in $[0.5,1]$, into (5) and (6)for comparison, then get the final evaluation results.

Computing results: when $\mathrm{x} \in[0,0.125]$, immature; when $\mathrm{x}$ $\in[0.125,0.375]$, less mature; when $x \in[0.375,0.75]$, more mature; when $\mathrm{x} \in[0.75,1)$,mature.

\section{APPLICATION EXAMPLE}

\section{A. Maturity Evaluation}

Adapting the evaluation index system shown in Fig. 1, using the above entropy fuzzy comprehensive evaluation model to evaluate the business district maturity of four stations, respectively is: Beijing railway station, Beijing west railway station, Shanghai railway station, Shanghai Hongqiao railway station.

The data of seven indexes of the above four railway stations are as follows:

TABLE I. FOUR RAILWAY STATION MATURITY EVALUATION INDEX DATA

\begin{tabular}{|c|c|c|c|c|c|c|c|}
\hline & $x_{1}$ & $x_{2}$ & $x_{3}$ & $x_{4}$ & $x_{5}$ & $x_{6}$ & $x_{7}$ \\
\hline$D_{1}$ & 286 & $1,110,000$ & 215326 & 167 & 32 & 110 & 25 \\
\hline$D_{2}$ & 221 & 900,000 & 330624 & 243 & 33 & 69 & 38 \\
\hline$D_{3}$ & 207 & 700,000 & 209368 & 197 & 23 & 65 & 39 \\
\hline$D_{4}$ & 38 & $2,000,000$ & 179520 & 322 & 4 & 18 & 8 \\
\hline
\end{tabular}

$x_{1}$ :resources, $x_{2}$ :gross resources area, $x_{3}$ :passenger flow, $x_{4}$ :the station train scale, $x_{5}$ :the reception capacity, $x_{6}$ :the catering ability, $x_{7}$ :traffic conditions. $D_{1}$ :Beijing railway station, $D_{2}$ :Beijing west railway station, $D_{3}$ :Shanghai railway station, $D_{4}$ :Hongqiao railway station.

1) With the Method of Entropy to Determine Weight, the Matrix of the Normalized Structure is as Follows:

$R=\left(\begin{array}{lllllll}1.0000 & 0.3153 & 0.2369 & 0.0000 & 0.9655 & 1.0000 & 0.5483 \\ 0.7379 & 0.1538 & 1.0000 & 0.4903 & 1.0000 & 0.5543 & 0.9677 \\ 0.6814 & 0.0000 & 0.1975 & 0.1935 & 0.6551 & 0.5108 & 1.0000 \\ 0.0000 & 1.0000 & 0.0000 & 1.0000 & 0.0000 & 0.0000 & 0.0000\end{array}\right)$

Computing results: $e_{j}=(0.9793,0.9734,0.9734,0.9752,0.9768,0.9797,0.9761)$

Difference function:

$g_{j}=(0.0206,0.0265,0.0265,0.0247,0.0231,0.0202,0.0238)$

The index weight vector is

$A=(0.1248,0.1599,0.1599,0.1494,0.1396,0.1223,0.1438)$

\section{2) Evaluating by Fuzzy Evaluation Method}

According to the classification of the maturity of railway station business district, it can be divided into four levels, $\mathrm{V}=$ (not mature, less mature, more mature, mature) as a fuzzy set.

Introduce data $\mathrm{A}$ and $\mathrm{R}$ into the formula, the result is:

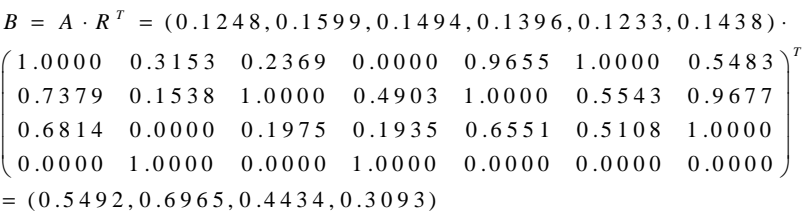

According to the range of the given maturity state $X$, judging bi by this method, we can get Beijing railway station b1 is $0.5492 \in[0.375,0.75]$, which belongs to a more mature state, and so on, Beijing west station, a more mature state; Shanghai station, a more mature state; and Shanghai Hongqiao station, a less mature state.

B. The Comparison of Business Districts Surrounding Beijing West Railway Station and Shanghai Hongqiao Station

1) The Comparison of Business Resources Quantity : From the number of business resources in business districts, comparing the situation of business districts around Beijing west railway station and Shanghai Hongqiao station, such as Table. 2.

TABLE II. BEIJING RAILWAY STATION AND BEIJING WEST STATION MAIN BUSINESS RESOURCES NUMBERS

\begin{tabular}{|c|c|c|c|c|c|}
\hline & caterings & hotels & supermarkets & $\begin{array}{c}\text { office } \\
\text { buildings }\end{array}$ & $\begin{array}{c}\text { bus } \\
\text { lines }\end{array}$ \\
\hline $\begin{array}{c}\text { Beijing west } \\
\text { railway station }\end{array}$ & 69 & 33 & 18 & 9 & 38 \\
\hline $\begin{array}{c}\text { Shanghai } \\
\text { Hongqiao } \\
\text { station }\end{array}$ & 18 & 4 & 11 & 0 & 8 \\
\hline
\end{tabular}

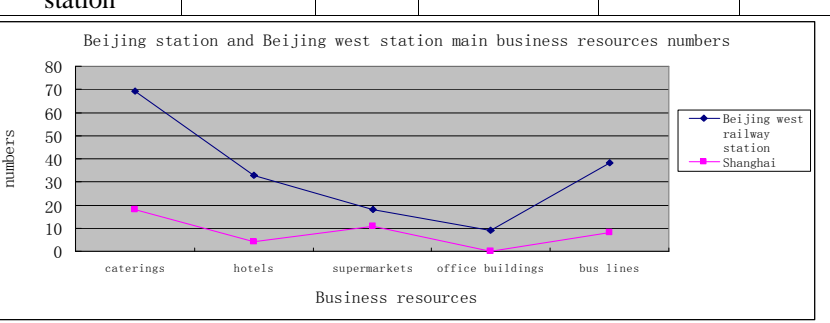

FIGURE III. BEIJING RAILWAY STATION AND BEIJING WEST STATION MAIN BUSINESS RESOURCES QUANTITY 
From Fig. 3,we can see that Shanghai Hongqiao station commercial resources is few and not rich enough number, compared to Beijing west railway station, the largest difference of Shanghai is in such aspects as the restaurant, hotel, office building.

2) The Comparison of Business Resources Average Distance: Taking the average distance from the station of five kinds of main business forms, into account to compare Beijing west railway station and Shanghai Hongqiao station business district, the farther the distance is, the greater the problems brought to dinner, accommodation, transportation of passengers will be, such as Table. 3 .

TABLE III. MAIN BUSINESS RESOURCES AVERAGE DISTANCE OF BEIJING RAILWAY STATION AND BEIJING WEST STATION

\begin{tabular}{|c|c|c|c|c|c|}
\hline & caterings & hotels & supermarket & $\begin{array}{c}\text { office } \\
\text { building }\end{array}$ & $\begin{array}{c}\text { bus } \\
\text { lines }\end{array}$ \\
\hline $\begin{array}{c}\text { Beijing west } \\
\text { railway station }\end{array}$ & 361.79 & 478.79 & 286.67 & 356.00 & 538 \\
\hline $\begin{array}{c}\text { Shanghai } \\
\text { Hongqiao } \\
\text { station }\end{array}$ & 0.00 & 1833.33 & 454.55 & 0.00 & 268.67 \\
\hline
\end{tabular}

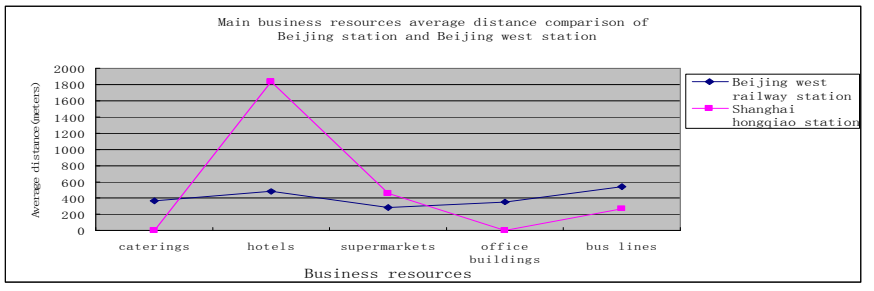

FIGURE IV. MAIN BUSINESS RESOURCES AVERAGE DISTANCE COMPARISON OF BEIJING RAILWAY STATION AND BEIJING WEST STATION

From Fig. 4, the catering and office buildings average distance from Shanghai Hongqiao station is 0, which is mainly because there is no catering and office buildings around Shanghai Hongqiao station, and 18 catering within the station cannot satisfy the needs of the meal of passengers and nearby office requirements, the hotel has the significantly greater average distance than Beijing west railway station, but the bus lines is relatively closer to the station, in aggregate, each item of resources of Shanghai Hongqiao station is far from the station and poorly convenient.

\section{The Development Strategy of Shanghai Hongqiao Station}

1) Catering : Shanghai Hongqiao station covers the largest area in the four stations, but only 18 caterings within and 0 around the station. So in catering, more investments should be increased to meet the eating and drinking demand of passengers. In the catering distance, the preliminary catering construction should be closer to the station, and then expanded around a concentric district.

2) Hotel: Restaurants and hotels are the business forms to meet the basic demand of the passengers. In management, investment should be attracted firstly to catering and hotels, which will also bring more profits to railway station, we should to meet the needs of different people; In the distance, firstly from the near to the distant, so a warm harbor can be provided to those who catch the train or arrive at the station before dawn.

3) Office Building : To achieve the mature state of Beijing west railway station business district, increase the awareness of the railway station, and provide the convenience of intercourse and office for more passengers, proper amount of office buildings should be established; in the distance, it should meet the middle circling of the station.

4) Bus Lines: In the future, Shanghai Hongqiao station will realize the definite function the increase of traffic is inevitable, so the bus lines is relatively less; in order to avoid poured jams causing a series of problems, we should increase the number of bus lines, properly considering the direction of the bus lines, the nearer the better.

\section{CONCLUSIONS}

The railway station business district is a fairly complex system with more influencing factors and evaluation indexes in design, using entropy value fuzzy comprehensive evaluation method to avoid the subjective factors of experts, which is suitable for measuring railway station business district maturity from scientific and reasonable aspect. in this paper, the railway station maturity will be divided into four levels: immature, less mature, more mature, mature. And eventually using membership degree to judge the maturity of the railway station business district, the greater the membership degree is, the more mature it will be. when $\mathrm{x} \in[0,0.125]$, belonging to immature; when $\mathrm{x} \in[0.125,0.375]$,less mature; when $\mathrm{x} \in$ $[0.375,0.75]$, more mature, when $\mathrm{x} \in[0.75,1]$, mature .This paper also take four stations such as Beijing west railway station, Shanghai railway station for example to conduct maturity evaluation, according with the actual phenomenon and validating the reliability of this index system. So, entropy fuzzy evaluation method for measuring the railway station business district maturity provides a development direction for the development of the business district around the railway station.

\section{REFERENCES}

[1] Yang Ziying. Research on the indicator system to evaluate the maturity of Beijing ReBAM.[D].Hebei:Hebei Normal University,2009.

[2] Wu Weiwei. Research on the Knowledge Process Project Management Maturity Model[D].Hunan: Hunan University,2009.

[3] Zhou Huicheng, Zhang Gaihong, Wang Guoli. Multi-objective decision making approach based on weights for reservoir flood control operation[J].2007,38(1).

[4] Xiao Yanlng, Liu Xiaojing, Liu Jianbo. The method of giving weight for performance indicator based on entropy method[J]. Journal of Daqing Petroleum Institute,2005, 29(1):107-109. 